\title{
The Effectiveness of Couple Therapy Based on Acceptance and Commitment on the Quality of Marital Relationship and Adjustment
}

\author{
Fatemeh Ansari Haghighi \\ Master of Educational Psychology, Islamic Azad University, \\ Marvdasht, Iran \\ pypg90@yahoo.com
}

\begin{abstract}
The aim of the current study is to investigate the effectiveness of couple therapy based on commitment and acceptance on the quality of marital relationships and adjustment of the couples of Bushehr. The statistical population of the current study includes all the couples, referring to the family consultation clinics in Bushehr in 2018. Using convenient sampling, 40 couples, referring to the consultation Aramesh clinic, Baran clinic, Mehr clinic in November and December, were randomly chosen and were appointed in two groups (20 in experimental groups and 20 in control group). The obtained data from the study were analyzed using covariance statistical analysis. The results indicated the effectiveness of couple therapy based on acceptance and commitment on the quality of marital relationship of the couples. It has been also effective on the permission of marital relationship, their satisfaction with marital relationship and tendency for marital relationship.
\end{abstract}

Keywords: Couple therapy based on commitment and acceptance, the quality of marital relationships, marital adjustment.

Received 2 January 2020/Accepted 15 May 2020 CJEHCP All rights reserved

\section{Introduction}

As the oldest and most fundamental basis of the society, family has existed from the advent of life and starts with the marital relationships of spouses. It is determined depending on the quality of this relationship, its sustainability. Marital adjustment is one of the most pivotal factors in determination of marital life stability and survival of marital life. Adjustment refers to coping with self and new conditions. In other words, adjustment refers to the ability of changing behavior, responding to the environmental changes so that the person makes a balance between what he wants and what the new conditions have caused. This adjustment does not necessarily mean satisfaction with the new conditions but the goal is to create minimum balance to achieve the idealities and needs. If the adjustment be more than expected range, it could lead 
to behavioral depression, dissatisfaction and non-pleasure, followed by aggression in the life environment (Ghasemzadeh, 2013). One of the effective variables on marital adjustment is the improvement of the quality of marital relationships. Marital relationship is a powerful and determining factor in marital life emotionally and physically (Laumann, Gagnon, Michael and Michaels, 2008) and intimacy in the quality of marital relationships is one of the indicators of closeness in relations and powerful index of love (Southern, 2010). The human being notices the quality of marital relationships as a way for expressing different types of emotions such as intimacy, love, wrath and aggression (Barash \& Lipton, 2010). Improving the quality of marital relationship between couples is of great importance due to close relationship with provision of emotional needs, marital satisfaction and as the result life quality improvement. Based on the studies, low quality of marital relationships in marital life has a direct relationship with marital satisfaction reduction (Edward \& Booth, 2006).

Since marital adjustment and the quality of marital relationship could lead to strength and sustainability in the couples, many studies have been conducted to determine the effectiveness of different treatments to promote it, one of the most important of which is couple therapy based on commitment and acceptance. This treatment has been known as one of common therapeutic approaches of behavioral treatment (Hayes, Masuda, Bissett, Luoma \& Guerrero, 2004).

The therapeutic approaches of third wave focus on the acceptance of beliefs against challenging them, mindfulness, cognitive defusion, describing the thoughts and feeling without giving meaning to them, the life based on the values and personal spiritualities. The main concentration of such treatments is more on the tolerance of symptom than reducing it as well as more flexible and adjusted methods of responding to the unpleased internal stimulus (Hayes, 2005).

The most clinically noticed treatment over the past years is acceptance and commitment-based one, abbreviated as ACT. The treatment is cognitive ones based on functional integration and is rooted in a new theory about language and cognition, known as relational mental framework 
(Hayes, Stroshal \& Wilson, 2008). Arab Vernosfaderani, Fatehizadeh, Bahrami, Alsadatjazayeri, Ebrahimi (2017) conducted a study, subjected to the effectiveness of ACT on marital adjustment of men, suffering bipolar disorder, type 2. In this study, 3 men with this disorder and their spouses, having marital problems, were selected through purposeful sampling method. Using single-case experimental plan and the scale of marital adjustment, the participants were evaluated in three levels of basic line, intervention and follow-up. The results showed a significant difference between the mean of scores of basic line levels and intervention. The effectiveness of ACT couple therapy was confirmed on the male, suffering bipolar disorder type 2. ACT-based couple therapy could lead to the increase of marital adjustment of men with bipolar disorder type 2 and reduced the rate of divorce in these patients.

Bawono (2019) explores Madurese women's happiness in early marriage with a phenomenological approach. Happiness of Madurese women who got married at an early age is studied through using qualitative method with phenomenological approach. The participants of this research are Madurese women living in Madura who got married under the age of 18 and are willing to be involved in this study. Data collection was through semi-structured interviews. The results of this research shows that Madurese women can lead a happy life in their early marriage; however, it is in contrast with other studies that indicate the occurrence of problems in early marriage.

Wulandari, Ginanjar, Purwono, Baydhowi, Purba (2019) did a study, subjected to health related quality of life model among patients with myocardial infarction in indonesia. This study tested three psychosocial factors (i.e. religious coping behaviour, cardiac anxiety and marital satisfaction) and two disease-related factors (i.e. left ventricular ejection fraction, comorbidity) in predicting health related quality of life in patients with post myocardial infarction in Indonesia. A cross sectional study included 170 patients with myocardial infarction was conducted. Proposed model was tested using structural equation modelling. Results revealed that cardiac anxiety has a significant negative relationship with health-related quality of life. Marital satisfaction was a significant moderator in the relationship between cardiac anxiety and health related quality of life. There were no significant relationships among patient's comorbidity, left 
ventricular ejection fraction, religious coping behaviour and health related quality of life. Results of the study shed the light of the importance of protective effects of patient's immediate environment in shaping patient's health related quality of life.

Akhavan Bitaghsir, SanaeiZaker, Navvabinejad and Farzad (2017) conducted a study, subjected to the comparison between the effectiveness of emotion-based couple therapy and ACT on the couples' marital adjustment and satisfaction. The method of the study was pretest-posttest follow-up quasi experimental. The statistical population of the study included all couples of Isfahan. The sample included 45 couples (15 couples in emotion-based group, 15 couples in ACT group and 15 couples in control group), randomly selected through convenient sampling method. Emotion-based group participated I4 session and ACT-based group in 12 sessions of group consultation while control group did not receive any intervention. Emotion-based couple therapy is more effective on marital adjustment and satisfaction than ACT-based treatment. The size of emotion-based treatment effect was 0.96 and the size effect of ACT treatment was 0.9.The findings of the current study can be used for clinical intervention to increase marital satisfaction and adjustment.

Watofa, Suryanto, \& Basuki (2019) in a qualitative research in November 2017, in Jayapura city study Papuan women's premarital sexual behavior and their attitude towards such an issue. Seven single Papuan women were observed and interviewed. Participants are all in reproductive age of 20-23. As it was expected, three of the participants did not accept the behavior. Individuals consider family factors, religion, and value systems as important factors that prevent from premarital sexual intimacy. Development of individual value system, practical education and development of positive self-esteem are factors that should be amplified in them to protect and avoid them from premarital sexual behavior.

Zimmerman, Prest ad Wetzel (2015) studied the effectiveness of ACT-based couple therapy on the increase of adjustment and improvement of marital status. They showed that ACT-based couple therapy is effective on the increase of marital adjustment and improvement of marital status. Russel (2015) has investigated the effectiveness of ACT-based couple therapy on marital 
adjustment. The statistical analyses of data showed that this treatment increases all four components of Spanier Dyadic Adjustment Scale that are marital satisfaction, correlation, agreement and love expression simultaneously. McCullough (2016) investigated the effectiveness of ACT-based couple therapy on marital adjustment. This study was conducted on 485 married males and females, having problems. It was shown that this type of treatment is effective and may lead to marital adjustment. Sehhat, Khanjani, Mohebbi, Shahsiah (20I6) studied the effect of ACT-based couple therapy on marital adjustment of women. They concluded that it has a significant effect on marital adjustment. It has been also significantly effective on satisfaction, correlation and love expression. Therefore, given the increase of divorce rate and reduction of adjustment and marital satisfaction over the two past decades, ACT-based couple therapy could increase marital adjustment and prevent divorce through helping the couples to develop effective solutions and find exceptions in the life.

Sharon (2017) investigated the effect of ACT-based couple therapy on level of differentiation from the main family and the quality of marital relationships of young couples. The findings indicated the effectiveness of ACT-based couple therapy on the increase of level of differentiation and independency from the main family to higher marital satisfaction and increase of the quality of marital relationship. Moreover, husband's dependency on his parents leads to emotional divorce and reduction of marital adjustment than wife's dependency on her parents.

Edward and Booth (2017) did a study, subjected to the effectiveness of ACT-based couple therapy on emotional divorce and marital adjustment in the women. They concluded that groups training based on ACT has had significant effect on emotional divorce and marital adjustment. This significant effect also involved the dimensions of satisfaction, correlation as well as love expression. Therefore, given the increase of divorce and decrease of marital adjustment and satisfaction over the past two decades, ACT-based couple therapy could increase marital adjustment and prevent divorce through helping the couples to develop effective solutions and find exceptions in the life.

Murat (2017) studied the effectiveness of ACT-based couple therapy on the acceptance of family's emotional atmosphere and the quality of couples' marital relationship. They concluded 
that ACT-based couple therapy affected emotional atmosphere of family positively. It has also affected the improvement of marital status can could increase the quality of it. Given the provided information, the current study can be used to identify the solutions for strengthening family relations in this pivotal class of society. Such studies are necessary for preventing the marital problems in problematic families through this treatment. Thus, the quality of marital relationship increases and marital adjustment is provided. Moreover, these results help the consulters and psychologists to notice ACT-based couple therapy for promoting the life of couples with marital problems. Given it, the aim of the current study is to check the effectiveness of ACT-based couple therapy on marital adjustment and the quality of marital relationship of the couples in Shiraz.

\section{Method}

The methodology of the study is pretest-posttest quasi-experimental with experimental and control group. The statistical population of the current study includes all the couples, referring to the family consultation clinics in Bushehr in 2018. Using convenient sampling, 60 couples, referring to the consultation Aramesh clinic, Baran clinic, Mehr clinicin November and December, were randomly chosen and they, who accepted to participate in the sessions of couple therapy based on acceptance and commitment, completed the questionnaire of martial adjustment and the quality of marital relationships on the couples of Bushehr. 40 couples with lower score were chosen as sample volume and randomly assigned in experimental and control groups (20 in experimental groups and 20 in control group).

Marital adjustment questionnaire. Spanier Dyadic Adjustment Scale (DAS) has been developed by Spanier in 1976 to evaluate the adjustment between couples or partners. The factor analysis showed that the scale measures four aspects of marital satisfaction, marital correlation, marital agreement and love expression. It includes a self-assessment questionnaire of 32 questions. The mental impressions of people about marital adjustment are also recorded. The scores of this questionnaire vary from 0 to $15 \mathrm{I}$. Higher or equal scores to 100 indicate a problem in marital relationships and lack of adjustment and family rapport. The related studies to the reliability and 
validity of DAS have been always positive. In fact, Bernstein (1989) has reported internal consistency coefficient of $96 \%$ and high validity rate for this scale in 1989. Spanier (1976) compared 218 people, living with their spouses, and 94 divorced one to calculate the validity of this scale (DAS). In this comparison, the mean of the two groups indicates a significant difference (at the level of $\mathrm{P}<0.00 \mathrm{I}$ ) and significant difference in subscales as well (at the level of $\mathrm{P}<0.00 \mathrm{I})$. To perceive whether the sizes of DAS can be accepted in the field of marital adjustment, the indicators of these scales shall be evaluated. The correlation of the sizes of these scales among people, living with their spouses, was 0.86 and for divorced one 0.88 . Spanier(1976) has estimated the validity of this scale in whole scores as 0.96 , indicating the significant internal consistency. Internal consistency of subscales has been also estimated within good to excellent: marital satisfaction scale: 0.94 , marital correlation: 0.81 , marital agreement: 0.90 and love expression: 0.73 . In the study of Mollazadeh (2002), to determine the validity, this questionnaire and Locke-Wallace Marital Adjustment Scale with reliability of $75 \%$ were simultaneously executed for 76 similar couples; the value was obtained as $90 \%$. Cronbach's alpha for the questionnaire is $94 \%$. To determine the reliability of the questionnaire, Hajabolzadeh (2002) executed retest method with the time gap of one week on a sample of 15 couples. To investigate the correlation of score, Pearson coefficient was used. correlation coefficient between male and female's scores was obtained in total score as 0.81 , the first subscale 0.68 , the second subscale $0.8 \mathrm{I}$, the third subscale 0.77 and the fourth subscale 0.78 . The reliability of this test in the current study was obtained 0.82 using Cronbach's alpha.

The questionnaire of the quality of marital relationships. this questionnaire has been developed by Samani $(201 \mathrm{I})$ to assess the quality of marital sexual relationship. It is a general scale for evaluating the quality of couples' sexual relationships. The content of the questionnaire has been developed based on clinical interviews with couples and evaluates three aspects of permission for marital relationship $(I, 2,3,4)$, marital relationship satisfaction $(5,5,7,8)$, tending for marital relationship $(9,10,11,12)$ in 12 statements of 5 items (totally agree to totally disagree). Each aspect includes 4 questions. Of course, some of questions are scored reversely. To clarify the scale structures, the main and effective components were analyzed. The results of analysis showed a three-sectional solution: I- the permission for making sexual 
relationship, 2- Sexual satisfaction and 3- sexual tendency. These factors have positive and significant correlation with marital satisfaction and negative and significant relationship with marital conflicts (Samani, 20I2). Also, because of high correlation between the aspects of this scale, respectively the highest quality of relationship in it referred to tending for sexual relationship and the least one to sexual relationships with total score. Cronbach's alpha coefficient for whole test 0.92 given the sample of 100 people. The coefficient for its subscales includes tendency 0.74, permission 0.78 and satisfaction 0.95 (Samani, 20I2). In the current study, the reliability of this test was obtained as 0.83 by Cronbach's alpha.

\section{Procedure}

The couples were first randomly chosen by the permission of the authorities of consulting clinics of Aramesh, Baran, Mehr in Bushehr and the required authorizations. They, who accepted to participate in the sessions of couple therapy based on acceptance and commitment, completed the questionnaire of martial adjustment and the quality of marital relationships on the couples. 40 couples with lower score were chosen as sample volume and randomly assigned in experimental and control groups. Experimental group participated in 8 sessions of I.5 hours for ACT-based couple therapy. The control group did not receive any interventions. The members of control group were informed of another test after two months from the test of first phase. After the end of training course, both groups participated in posttest and completed the mentioned questionnaires again. The data were analyzed by appropriate statistical tests. The subjects of training courses have been proposed in the appendix.

The first session: introducing the therapist, introducing the participants in the group session with present couples, determining the number of sessions, profound explanation of ACT principles, practicing in class for familiarizing and trusting of members to each other more (couples). Second session: we explain the acceptance and discuss it with the couples. Third session: reviewing the practices and homework, weakening cognitive integration (cognitive defusion), in this part, the couples are helped to differentiate between what they experience for better perception (their thoughts and emotions are other than themselves). Fourth session: reviewing the practice of the previous session, looking at thoughts instead of looking by 


\section{Journal of Educational, Health and Community Psychology Vol 9, No 2, 2020 E-ISSN 2460-8467}

thoughts. We taught the couples to explain their behaviors and changed some of verbal words of them. Fifth session: reviewing the previous session practice, contacting the present time, reducing the tendency of person for being in absolute future or past.

Sixth session: reviewing the practice of the previous session, the main goal is to help the couples to stabilize a constant a good feeling in them. Seventh session: reviewing the practice of the previous session, the members state the values and their good determination and therapist draw a conclusion. Eighth session: reviewing the practice of the previous session, commitment, insistence process, changing process.

\section{Result}

To explain the intended variables, descriptive indicators, including mean, standard deviation of marital adjustment and the quality of marital relationships and its components have been proposed in control and experimental group in tables $I$ and 2.

\section{Table I}

The mean, standard deviation of control group in pretest and posttest

\begin{tabular}{|c|c|c|c|c|c|}
\hline \multirow{9}{*}{ 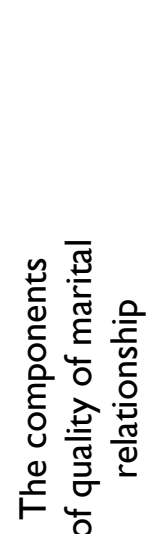 } & \multicolumn{2}{|c|}{ Control group variable } & \multirow{2}{*}{$\begin{array}{c}\text { Frequency } \\
20\end{array}$} & \multirow{2}{*}{$\begin{array}{l}\text { Mean } \\
12.0 \mid\end{array}$} & \multirow{2}{*}{$\begin{array}{c}\begin{array}{c}\text { Standard } \\
\text { deviation }\end{array} \\
6.71\end{array}$} \\
\hline & \multirow[t]{2}{*}{ Marital adjustment } & Pretest & & & \\
\hline & & Posttest & 20 & 12.15 & 6.55 \\
\hline & \multirow{2}{*}{$\begin{array}{l}\text { Permission of marital } \\
\text { relationship }\end{array}$} & Pretest & 20 & 2.85 & 1.13 \\
\hline & & Posttest & 20 & 3.10 & 1.20 \\
\hline & \multirow{2}{*}{$\begin{array}{l}\text { Marital relationship } \\
\text { satisfaction }\end{array}$} & Pretest & 20 & 1.55 & 1.31 \\
\hline & & Posttest & 20 & 1.70 & 1.27 \\
\hline & \multirow{2}{*}{$\begin{array}{l}\text { Tendency in marital } \\
\text { relationship }\end{array}$} & Pretest & 20 & 2.01 & 1.55 \\
\hline & & Posttest & 20 & 2.15 & 1.59 \\
\hline & \multirow{2}{*}{$\begin{array}{l}\text { The quality of marital } \\
\text { relationships }\end{array}$} & Pretest & 20 & 12.01 & 6.71 \\
\hline & & Posttest & 20 & 14.15 & 6.49 \\
\hline
\end{tabular}




\section{Journal of Educational, Health and Community Psychology \\ Vol 9, No 2, 2020 E-ISSN 2460-8467}

Fatemeh

Mean standard deviation of control group in pretests and posttest of marital adjustment, the quality of marital relationships and its components are seen in table I.

\section{Table 2}

The mean, standard deviation of experimental group in pretest and posttest

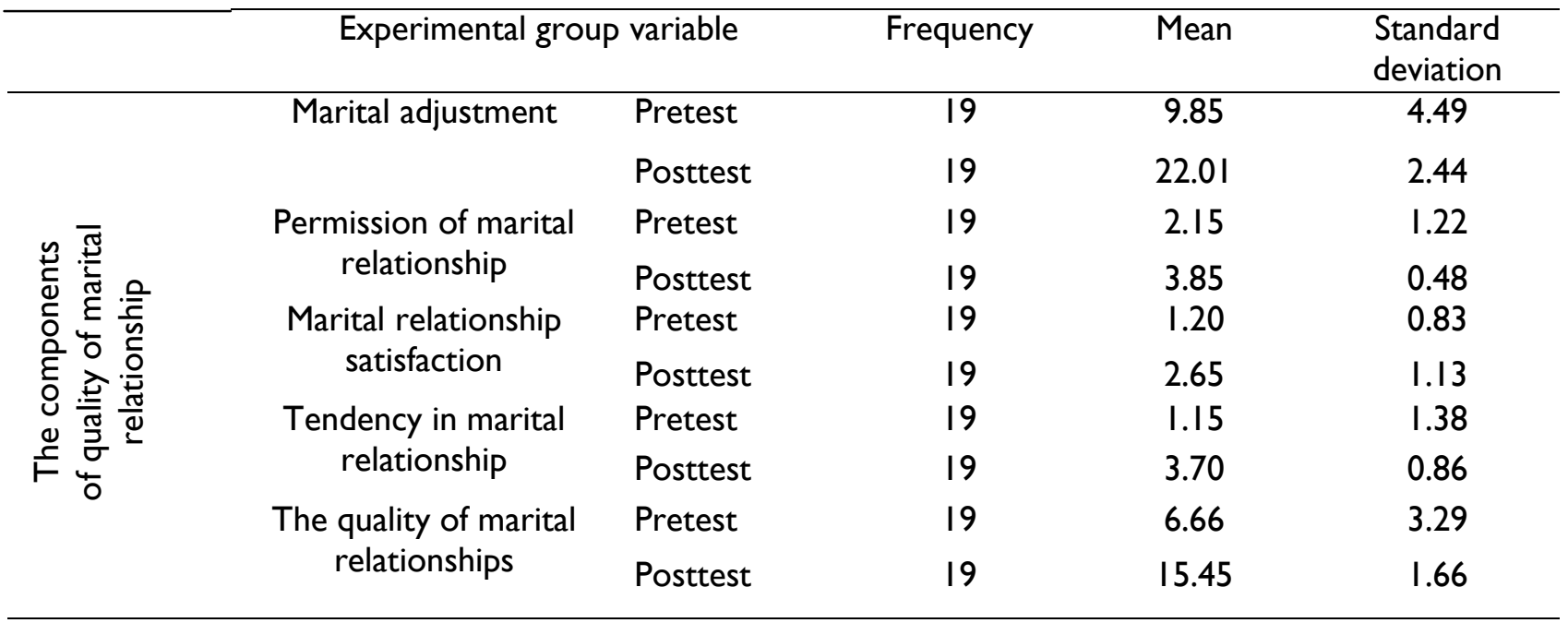

Mean standard deviation of experimental group in pretests and posttest of marital adjustment, the quality of marital relationships and its components are seen in table 2 . The scores in all variables of posttest are more than pretest. The highest score in the mean of experimental group in the aspects of the quality of marital relationship refers to the permission of marital relationship in posttest $(3.85)$.

To investigate the effectiveness of ACT-based couple therapy on the quality of marital relationships, covariance analysis has been used. Levin test is used for convergence of variance in experimental groups. The results of this study have been proposed in tables 3,4 and 5. 


\section{Journal of Educational, Health and Community Psychology \\ Vol 9, No 2, 2020 E-ISSN 2460-8467}

Fatemeh

Table 3

Levin test for determining the equality of the quality marital relationship variance

\begin{tabular}{lc}
\multicolumn{2}{c}{ The quality of marital relationships } \\
\hline The value of Levin F & 2.38 \\
The first degree of freedom & 1 \\
The second degree of freedom & 38 \\
Significance level & 0.13
\end{tabular}

As indicated in table 3, the variances of both groups are convergent so covariance analysis can be used.

Table 4

To investigate the convergence of regression slopes

\begin{tabular}{cccccc}
\hline Index & Sum of squares & Df & MS & f & sig \\
\hline Pretest group* & 50.27 & I & 50.27 & 43.44 & 0.06 \\
\hline
\end{tabular}

As presented in table 4, the interaction between the group and pretest is not statistically significant and so the convergence of regression slope is confirmed for covariance test.

Table 5

The results of covariance analysis of ACT-based couple therapy on the quality of marital relationships

\begin{tabular}{|c|c|c|c|c|c|c|}
\hline The source of changes & $\begin{array}{l}\text { Sum of } \\
\text { squares }\end{array}$ & $d f$ & MS & $f$ & sig & $\begin{array}{l}\text { Partial eta } \\
\text { square }\end{array}$ \\
\hline Pretest & 227.91 & 1 & 227.91 & 196.98** & 0.0001 & 0.84 \\
\hline $\begin{array}{l}\text { Difference between the } \\
\text { groups }\end{array}$ & 230.07 & I & 230.07 & $198.85^{* *}$ & 0.0001 & 0.84 \\
\hline Error & 41.65 & 36 & 1.15 & ----- & ----- & $---002 D$ \\
\hline Total & 7930 & 40 & ----- & ----- & ---- & ---- \\
\hline
\end{tabular}

Note $=\mathrm{P}^{*}<0.05 \quad \mathrm{P} * *<0.01$

As indicated in table 5 , with $99 \%$ of confidence, ACT-based couple therapy has been effective on the quality of couples' marital relationships. 


\section{Journal of Educational, Health and Community Psychology \\ Vol 9, No 2, 2020 E-ISSN 2460-8467}

Fatemeh

To investigate the effectiveness of ACT-based couple therapy on the components of quality of marital relationships, covariance analysis has been used. Levin test is used for convergence of variance in experimental groups. The results of this study have been proposed in tables 6, 7, 8, 9 and 10.

Table 6

Levin test for determining the equality of marital relationship components variances

\begin{tabular}{cccc}
\hline & $\begin{array}{c}\text { The permission of } \\
\text { marital relationship }\end{array}$ & $\begin{array}{c}\text { marital relationship } \\
\text { satisfaction }\end{array}$ & $\begin{array}{c}\text { the tendency in marital } \\
\text { relationship }\end{array}$ \\
\hline $\begin{array}{c}\text { The value of Levin } \\
\text { F }\end{array}$ & 1.04 & $30.6 \mathrm{I}$ & 0.99 \\
$\begin{array}{c}\text { The first degree of } \\
\text { freedom }\end{array}$ & $\mathrm{I}$ & $\mathrm{I}$ & $\mathrm{I}$ \\
$\begin{array}{c}\text { The second degree } \\
\text { of freedom }\end{array}$ & 38 & 38 & 38 \\
Significance level & 0.29 & 0.06 & 0.32 \\
\hline
\end{tabular}

As indicated in table 6 , the variance in both groups is convergent so covariance analysis can be used.

Table 7

The convergence of regression slopes

\begin{tabular}{ccccccc}
\hline Index & & $\begin{array}{c}\text { Sum of } \\
\text { squares }\end{array}$ & Df & MS & $\mathrm{f}$ & sig \\
\hline $\begin{array}{c}\text { The permission of } \\
\text { marital relationship }\end{array}$ & $\begin{array}{l}\text { Pretest } \\
\text { group* }\end{array}$ & 12.52 & I & 12.52 & 54.38 & 0.08 \\
$\begin{array}{c}\text { The permission of } \\
\text { marital relationship } \\
\text { The permission of } \\
\text { marital relationship }\end{array}$ & $\begin{array}{c}\text { Proup* } \\
\text { group }\end{array}$ & 0.48 & I & 0.48 & 0.93 & 0.34 \\
group* & 5.42 & I & 5.42 & 17.87 & 0.056 \\
\hline
\end{tabular}




\section{Journal of Educational, Health and Community Psychology Vol 9, No 2, 2020 E-ISSN 2460-8467}

As presented in table 7 , the interaction between the group and pretest is not statistically significant and so the convergence of regression slope is confirmed for covariance test.

\section{Table 8}

The results of covariance analysis of ACT-based couple therapy on the permission for marital relationships

\begin{tabular}{|c|c|c|c|c|c|c|}
\hline $\begin{array}{c}\text { The source of } \\
\text { changes }\end{array}$ & $\begin{array}{l}\text { Sum of } \\
\text { squares }\end{array}$ & $\mathrm{df}$ & MS & $f$ & sig & $\begin{array}{c}\text { Partial eta } \\
\text { square }\end{array}$ \\
\hline Pretest & 13.34 & I & 13.34 & $57.95^{* *}$ & 0.0001 & 0.61 \\
\hline $\begin{array}{l}\text { Difference between } \\
\text { the groups }\end{array}$ & 21.10 & I & 21.10 & $91.65^{* *}$ & 0.0001 & 0.71 \\
\hline Error & 8.29 & 36 & 0.23 & ----- & ----- & ---- \\
\hline Total & 521 & 40 & ----- & ----- & ---- & ---- \\
\hline
\end{tabular}

As indicated in table 8 , with $99 \%$ of confidence, ACT-based couple therapy has been effective on the permission of couples' marital relationships.

\section{Table 9}

The results of covariance analysis of ACT-based couple therapy on marital relationships satisfaction

\begin{tabular}{|c|c|c|c|c|c|c|c|}
\hline $\begin{array}{l}\text { The source of } \\
\text { changes }\end{array}$ & $\begin{array}{l}\text { Sum of } \\
\text { squares }\end{array}$ & $\mathrm{df}$ & MS & $\bar{f}$ & sig & $\begin{array}{l}\text { Partial } \\
\text { square }\end{array}$ & eta \\
\hline Pretest & 2.60 & I & 2.60 & $51.95^{* *}$ & 0.0001 & 0.59 & \\
\hline $\begin{array}{l}\text { Difference between } \\
\text { the groups }\end{array}$ & 4.03 & I & 4.03 & $7.87^{* *}$ & 0.008 & 0.18 & \\
\hline Error & 18.44 & 36 & 0.51 & ----- & ----- & ---- & \\
\hline Total & 161 & 40 & ----- & ----- & ---- & ---- & \\
\hline
\end{tabular}
Note $=\mathrm{P} *<0.05 \quad \mathrm{P} * *<0.01$

As indicated in table 9, with $99 \%$ of confidence, ACT-based couple therapy has been effective on couples' marital relationships satisfaction. 


\section{Journal of Educational, Health and Community Psychology \\ Vol 9, No 2, 2020 E-ISSN 2460-8467}

Fatemeh

The results of covariance analysis of ACT-based couple therapy on marital relationships tendency

\begin{tabular}{|c|c|c|c|c|c|c|}
\hline $\begin{array}{l}\text { The source of } \\
\text { changes }\end{array}$ & $\begin{array}{l}\text { Sum of } \\
\text { squares }\end{array}$ & $d f$ & MS & f & sig & $\begin{array}{l}\text { Partial eta } \\
\text { square }\end{array}$ \\
\hline Pretest & 42.27 & I & 42.27 & 139.43** & 0.0001 & 0.79 \\
\hline $\begin{array}{l}\text { Difference between } \\
\text { the groups }\end{array}$ & 39.65 & I & 39.65 & $|30.8|^{* *}$ & 0.0001 & 0.78 \\
\hline Error & 10.91 & 36 & 0.30 & ----- & ----- & ---- \\
\hline Total & 429 & 40 & ----- & ----- & --- & ---- \\
\hline
\end{tabular}

Note $=P^{*}<0.05 \quad P^{* * *}<0.01$

As indicated in table 10, with $99 \%$ of confidence, ACT-based couple therapy has been effective on couples' marital relationships tendency.

To investigate the effectiveness of ACT-based couple therapy on the marital adjustment, covariance analysis has been used. Levin test is used for convergence of variance in experimental groups. The results of this study have been proposed in tables II, I2 and I3.

Table II

Levin test for determining the equality of marital adjustment

\begin{tabular}{cc}
\hline & Marital adjustment \\
\hline The value of Levin F & 1.48 \\
The first degree of freedom & 1 \\
The second degree of freedom & 0.38 \\
\hline Significance level & 0.23 \\
\hline
\end{tabular}

As indicated in table II, the variances of both groups are convergent so covariance analysis can be used. 


\section{Journal of Educational, Health and Community Psychology \\ Vol 9, No 2, 2020 E-ISSN 2460-8467}

Fatemeh

Table 12

To investigate the convergence of regression slopes

\begin{tabular}{cccccc}
\hline Index & Sum of squares & Df & MS & f & sig \\
\hline Pretest group* & 83.47 & I & 83.47 & 35.78 & 0.06 \\
\hline
\end{tabular}

As presented in table 4, the interaction between the group and pretest is not statistically significant and so the convergence of regression slope is confirmed for covariance test.

Table 13

The results of covariance analysis of ACT-based couple therapy on marital adjustment

\begin{tabular}{|c|c|c|c|c|c|c|}
\hline $\begin{array}{c}\text { The source of } \\
\text { changes }\end{array}$ & $\begin{array}{l}\text { Sum of } \\
\text { squares }\end{array}$ & $\mathrm{df}$ & MS & f & sig & $\begin{array}{l}\text { Partial eta } \\
\text { square }\end{array}$ \\
\hline Pretest & 477.16 & 1 & 477.16 & $204.55^{* *}$ & 0.0001 & 0.84 \\
\hline $\begin{array}{l}\text { Difference between } \\
\text { the groups }\end{array}$ & 456.74 & 1 & 456.74 & 195.79** & 0.0001 & 0.85 \\
\hline Error & 83.97 & 36 & 2.33 & ----- & ---- & ---- \\
\hline Total & $1460 \mid$ & 40 & ----- & ----- & --- & --- \\
\hline
\end{tabular}

Note $=\mathrm{P}^{*}<0.05 \quad \mathrm{P}^{* *}<0.01$

As indicated in table 13, with $99 \%$ of confidence, ACT-based couple therapy has been effective on couples' marital adjustment.

\section{Discussion}

As indicated in table 4, ACT-based couple therapy significantly affects the quality of marital relationships. The results of this study are consistent with the results of Sharon (2017) and Murat (2017). To explain this hypothesis, since ACT-based couple therapy helps the couples for intellectual changes and selection of healthy and suitable behaviors, it can be an effective step towards mental and spiritual calmness, enabling them to share their needs, demands and interests with their spouses, express their love and handle the problems of family well. This 
treatment also causes that couples be more positive towards and aware of life and the quality of marital relationships, leading to discovery of values in the spousal relationship and commitment to it. In other words, ACT-based couple therapy reduces the marital conflicts or disagreement between personal demands of them. Such couples are more flexible. In fact, they can cope with life challenges better, leading to increase of quality of marital relationships, life satisfaction and increase of forgiveness in their life. This treatment enables the couples to get rid of stressful emotions and encourage the positive cognitive growth of the spouse. It also enables them to continue their relationship and flourish it so intimacy is created which is an important tool for maintaining the sustainable and long-term relations. It reduces physical and mental fatigue and increases the quality of marital relationship in the couples.

As indicated in tables 8, 9 and 10, ACT-based couple therapy significantly affect the components of the quality of marital relationship (the permission for marital relationship, marital relationship satisfaction and tendency in marital relationship). To explain such hypothesis, when the couples have ACT-based couple treatment, they can accept the emotions of their parties and ultimately it increases the permission for marital relationship, marital relationship satisfaction and tendency in marital relationship. In other words, such couples get committed to their values in life and will have more concentration on the increase of their life, reducing the marital conflicts and finally increasing the permission for marital relationship, marital relationship satisfaction and tendency in marital relationship. These couples could minimize marital conflicts and find a way for solving their problems, which other couples cannot solve it alone and ultimately it increases the permission for marital relationship, marital relationship satisfaction and tendency in marital relationship. Also when the couples have ACT-based couple treatment, they accept the hardships of the life and try for a rich, complete and significant life. They are more committed to the action, enriching their life. It reduces marital conflicts or unrealistic expectations and irrational thoughts and life ups and downs and ultimately it increases the permission for marital relationship, marital relationship satisfaction and tendency in marital relationship. Moreover, this treatment can make couples more committed to clarification of their values in the life and prevent them from sorrows. In fact, such couples can create a meaningful life through controlling the pains, sorrows and stresses effectively that ultimately it increases the permission 
for marital relationship, marital relationship satisfaction and tendency in marital relationship. In other words, this treatment leads to a kind of mental flexibility in the couples which increases the permission for marital relationship, marital relationship satisfaction and tendency in marital relationship.

As indicated in table 13, ACT-based couple therapy significantly affects marital adjustment. The results of this study are consistent with the results of Arab Vernosfaderani, Fatehizadeh, Bahrami, Alsadatjazayeri, Ebrahimi (2017), AkhavanBitaghsir, Sanaeizaker, Navvabinejad, Farzad (2017), Zimmerman, Prest ad Wetzel (20I5), Russel (20I5), Mccoulaf (20I6), Sehat, Khanjani, Mohebbi, Shahsiah (2016), Edward and Booth (2017). To explain this hypothesis, when the couples have ACT-based couple treatment, there will be a deep emotional linkage between them, which could lead to pleasure of interaction with each other and kind of powerful emotional attachment and mutual with each other and finally cause the increase of marital adjustment. In other words, such couples have a kind of internal commitment and obligation to each other which may lead to commitment to the life. If these couples make a mistake in their life. Instead of attributing to the external factors, they try to correct it and finally cause the increase of marital adjustment or reduction of unrealistic expectations and irrational thoughts and life ups and downs. Moreover, the treatment leads to acceptance of emotions and thoughts and make couples to be more committed to their values in life and concentrate more on the increase of life quality, which can lead to increase of marital adjustment. In other words, when the couples have such treatment, they will be enabled to continue their relationship and flourish it so intimacy is created which is an important tool for maintaining the sustainable and longterm relations which increases marital adjustment.

\section{Conclusion}

The purpose of acceptance and commitment therapy is natural expression of thoughts and emotions, eradication of conflicts between spouses and starting off new and positive communications to expand adjustment that gradually results in decreasing exhaustion. Couples 
in different ages of their marital life may have conflicts and discords and may constantly attempt to change each other. They try to avoid freeing their minds from their interpersonal disagreements and they use interpersonal controlling methods and hostility towards each other. In this therapy, couples' intimacy and adjustment are improved by acceptance, not having experiential avoidance, not using controlling methods, increasing mindfulness, determining values, modifying expectations, reasoning, and decreasing judgment. This improvement is perceptible by couples and works as a natural booster of enthusiasm to continue their therapy which can lead to an increase in the quality of sexual intercourses and adjustment.

Acceptance and commitment therapy persuades people to accept thought process as a necessary and real action for psychological adjustment and it decreases couples' negative cognition schema. In other words, acceptance commitment therapy enables people to manage difficult and critical situations more effectively. In fact, this therapy increases sincere responses and positive emotional exchange in couples and help them find their deepest desires and understand the importance of marital relationship and consequently it increases couples' marital adjustment and the quality of their sexual intercourses.

Moreover, acceptance and commitment therapy teaches people that everybody has his own pain. All our thoughts, emotions, physical symptoms, desires and memories are clean pain but if they are over emphasized and highlighted, dirty pain is created which is unpleasant. Therefore, by cognitive diffusion one can live happily and optimistically. In fact, ACT is the treatment of emotional avoidance and expansion of cognitive content and it creates and keeps commitment in behavioral changes. Thus, couples of the experimental group can remarkably decrease their sensitivity and controlling manners by practices of acceptance and mind concentration and therefore their marital agitation and conflicts are decreased meaningfully. 


\section{References}

Akhavan Bitaghsir, Zahra; Sanaeizaker, Bagher; Navvabinejad, Shokouh and Farzad, Valiollah (2017).The comparison of effectiveness of emotion-based couple therapy and ACT-based treatment on couples' marital satisfaction and adjustment, Teaching and promoting Iran health (Persian), 5(2) I2I-128.

Arab Vernosfaderani, Mostafa; Fatehizadeh, Maryam; Bahrami, Fatemeh; Alsadatjazayeri, Rezvan; Ebrahimi, Amorollah (2017). The effectiveness of ACT-based couple therapy on marital adjustment of men, suffering bipolar disorder type 2.The Journal of Behavioral Science Researches, 15(3), 269-276.

Barash, D. P., \& Lipton, J. E. (2010). Gender gap: The biology of male-female differences. London: Transaction Publishers.

Bawono, Y., \& Suryanto (2019) Does early marriage make women happy? A phenomenological finding from Madurese women, Journal of Educational, Health and Community Psychology, $8(1), 85-100$.

Edward, J. N., \& Booth, A. (2006) Sexuality, marriage, and well-being: The middle years. In A. S. Rossi (Ed.), Sexuality across the life course (pp. 233-259). Chicago: University of Chicago Press.

Edward, J. N., \& Booth, A. (2017) Effect couple therapy based on commitment and acceptanceon emotional divorce and marital adjustment in women. Journal of Marriage and Family, 63(2),526-539.

Ghasemzadeh, J. (20I3). The relationship between marital adjustment with life satisfaction and the life quality of couples of Isfahan. Master thesis. Isfahan University.

Hayes S. C, Masuda, A., Bissett, R., Luoma, J., \& Guerrero, L. F. (2004). DBT, FAP, and ACT: How empirically oriented are the new behavior therapy technologies? Behav Ther, 35, 3554.

Hayes S. C. (2005). Acceptance and commitment therapy, relational frame theory, and the third wave of behavioral and cognitive therapies. Behav The,. 35, 639- 65.

Hayes, Steven. C. Strosahl, Kirk.,\& Wilson, K. G. (2008). Acceptance and commitment therapy: An experiential approach tobehavior change. New York: Guilford press.

Laumann, E. O., Gagnon, G. H., Michael, R. T., \& Michaels, S. (2008) .The social organization of sexuality: Sexual practices in the United States. Chicago: University of Chicago Press. 


\section{Journal of Educational, Health and Community Psychology Vol 9, No 2, 2020 E-ISSN 2460-8467}

McCullough, M. (2016). The effectiveness of couple therapy based on commitment and acceptance on marital adjustment. Current Direction in Psychological Science. 10(4), I I I- I 22.

Murat, T. (2017) The effectiveness of couple therapy based on commitment and acceptance on the emotional atmosphere of family and quality of sex. African Journal of Family, 5(9), Pp. 3614-3622

Russell M. (2015) The effectiveness of couple therapy based on commitment and acceptance of marital adjustment. [Dissertation]. Prescott, Arizona

Sehat, N., Sehat, F., Khanjani, S, Mohebi, S., \& Shahsiah, M. (2016)The effectiveness of couple therapy based on commitment and acceptance of marital adjustment In Women, Journal of marriage and family, 63(2),526-539.

Sharon S. N. (2017) Couple therapy based on commitment and acceptance on the principle of differentiation families and quality of sex of young couples, Science and Practice, 15, 286295

Southern, S. (2010) Facilitating sexual health: Intimacy enhancement techniques for sexual dysfunction. Journal of Mental Health Counseling, 21, 15-33.

Wulandari, D. Ginanjar, A.S. Purwono, U. Baydhowi, N., \& Purba. F. D. (2019) Health Related Quality of Life Model among Patients with Myocardial Infarction in Indonesia, Journal of Educational, Health and Community Psychology, Vol 8, No 3, E-ISSN 2460-8467

Watofa, Y. F., Suryanto, \& Basuki, H. (2019) Premarital sexual behavior among Papua women: a Qualitative research, Health and Community Psychology, 8(2), I59-I76.

Zimmerman T. S., Prest L. A., \& Wetzel BE.(20I5) Effectiveness Couples based on commitment and acceptance therapy on adaptation and improvement of marital status. J FamTher; 19 (2): $125-44$. 